\title{
Vicente's poison frog (Oophaga vicentei) in the wild: calling activity, bioacoustics and diet
}

\author{
ERIC E. FLORES ${ }^{1,2,3^{*}}$, ABEL BATISTA $^{4}$, VITERBO RODRIGUEZ ${ }^{5}$ \& RACHEL A. PAGE ${ }^{6}$
}

${ }^{1}$ INDICASAT AIP, BIdg. 219, City of Knowledge, Clayton, Panama, Republic of Panama

${ }^{2}$ Panama Wildlife Conservation, 1 Powis Mews, London, W11 1JN, UK

${ }^{3}$ Coiba Scientific Station (COIBA AIP), City of Knowledge, Clayton, Panama, Republic of Panama

${ }^{4}$ Universidad Autónoma de Chiriquí, Vicerrectoria de Investigación y Postgrado, Ciudad Universitaria El Cabrero David, Chiriquí, 427, Republic of Panama

${ }^{5}$ Universidad de Panamá, Centro Regional Universitario de Veraguas, CCIMBIO-COIBA, Calle décima, Santiago, Republic of Panama ${ }^{6}$ Smithsonian Tropical Research Institute, Luis Clement Ave., Tupper Building 401, Balboa, Ancón, Panamá, Republic of Panama *Corresponding author e-mail: sailax1@gmail.com

\begin{abstract}
Calling activity, bioacoustics and the diet of males is reported for three different populations of Oophaga vicentei in central Panama. Calling activity was predicted by time of day, season and temperature with peaks between 08:00 $\mathrm{h}$ to 10:00 $\mathrm{h}$ and was more frequent during the dry season. Only at one location was calling activity positively correlated with air temperature. The temperature was also positively correlated with call repetition rates and negatively with call duration. Within the ten first calls of a call-bout, there was a cline variation in dominant frequency, call duration and silent intervals. The stomach contents of males comprised mainly insects but also a large number of oribatid mites.
\end{abstract}

\section{INTRODUCTION}

V icente's poison frog Oophaga vicentei (Jungfer, Weygoldt \& Juraske, 1996) is an arboreal dendrobatid frog endemic to Panama. Since its description, few data on the natural history or ecology of this species have been published. Oophaga vicentei is included in appendix II of CITES and is considered as data deficient by the International Union for Conservation of Nature (IUCN SSC Amphibian Specialist Group, 2019).

Acquiring baseline ecological data is important not only to contribute to our understanding of the natural history of a species but also, critically, for establishing and monitoring its conservation status and ranking (Rodrigues et al., 2006). Here we present data from observations in the wild on the calling activity, differences in bioacoustics, and diet in three O. vicentei populations along the Pacific and Caribbean slopes in the Santa Fe National Park of central Panama.

\section{MATERIALS AND METHODS}

\section{Study site}

Field work was conducted within, and in the buffer zone of, the Santa Fe National Park (SFNP) located in the north of Veraguas province in central Panama. Coordinates of the exact study sites are not provided to avoid the threat of illegal collection. The study sites were located on the continental divide (Loma Grande, $750 \mathrm{~m}$ a.s.I.), and on the Pacific (Isleta, $460 \mathrm{~m}$ a.s.I.) and Caribbean (Alto Ortiga, $380 \mathrm{~m}$ a.s.I.) slopes of the park. In addition, we provide preliminary data from previous surveys of two other populations from Santa Fe and one from the Caribbean slope in the district of Donoso (Fig. 1). Field data from the first three populations were collected during the end of rainy season 2015 (November), dry season
2016 (January to April) and rainy season 2016 (May to September), so season was coded as either 'dry' or 'rainy' in the analysis. In addition, oscillograms and spectrograms of $O$. vicentei and for most Panamanian species within the genus are shown for further comparison (Supplementary materials, Fig. 1).

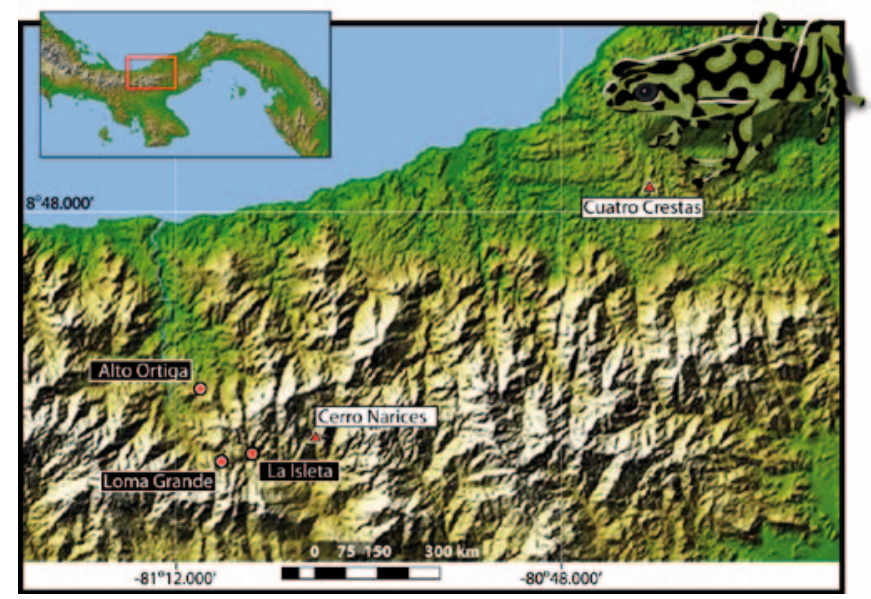

Figure 1. Distribution map of populations of the three focal O. vicentei study sites: Loma Grande (on the Continental Divide), La Isleta (on the Pacific slope), Alto Ortiga (on the Caribbean slope), and the two additional sites included in the bioacoustics analysis: Cerro Narices (Pacific slope) and Cuatro Cuestas (Caribbean slope)

\section{Biometric measurements}

We located focal males by searching for their calls, and then climbing trees with the aid of a wooden ladder. We used nitrile gloves (Safe-touch: Dynarex New York, USA) for safe capture and handling. Snout-to-vent length was calculated 
from photographed individuals (with Canon PowerShot D30: 12.1 megapixels: Canon Inc., Tokyo, Japan) using Image J (Rasband, 1997). Body mass was measured to the nearest $0.1 \mathrm{~g}$ using a portable balance (AWS-100: American Weigh Scales Inc., Georgia, USA).

\section{Calling activity and environmental data}

As with other dendrobatids, $O$. vicentei is active during the day, therefore the call-bouts of males were noted during daylight hours as a proxy for calling activity. Daytime was divided in two main periods; morning (07:00 $\mathrm{h}-10: 00 \mathrm{~h})$ and afternoon (14:00 $\mathrm{h}-17: 00 \mathrm{~h})$ and the number of call-bouts heard was quantified in each three-hour period. Based on our field experience, upon arrival at the site, we waited $30 \mathrm{~s}$ before initiating acoustic recordings which did not cause any appreciable disturbance (Dorcas et al., 2010). We recorded the temperature and relative humidity every 8 minutes, using a portable thermo-hygrometer (model Atmos Skywatch: JDC Electronics, Switzerland). Site position and elevation were recorded with a GPS (Garmin eTrex 20x: Garmin International Inc., Olathe, KS, USA). Like other dendrobatids, $O$. vicentei is territorial (Lötters et al., 2007). We identified the territory of a single vocalising male at Loma Grande, and recorded its individual calling behaviour over the course of $24 \mathrm{~h}$. We placed a long-term recorder (Wildlife acoustics Song Meter $\mathrm{SM} 4)$ in front of the focal male (0.5 to $1.5 \mathrm{~m}$ away from it and $2 \mathrm{~m}$ above ground), and set it to record from $12: 38 \mathrm{~h}$ to $12: 15 \mathrm{~h}$ the next day ( $9-10$ July 2017). Audio files were saved every 15 minutes and opened in Raven 1.5.0, as page sound ( 3 min duration, page increment $90 \%$ ); every call from the first day was analysed using the Band Limited Energy Detector tool, with the following preset: Minimum Frequency $4700 \mathrm{~Hz}$, Maximum Frequency $6600 \mathrm{~Hz}$, Minimum Duration: $0.19156 \mathrm{~s}$, Maximum duration $0.3541 \mathrm{~s}$, Minimum separation: 0.09288 s, Noise: SNR Threshold (dB) 28.0 above. The remaining parameters were set as default. It was not possible to analyse a single call from the next day, as the male moved farther from the microphone, and when trying to analyse calls under the interactive detectors, proper identifications were not possible due to an increase in background noise. As such, entire calls were only analysed for the morning recordings.

\section{Bioacoustics}

Male advertisement calls were recorded from the ground using a Marantz PMD660 handheld digital recorder (Marantz Professional, Cumberland, USA), using a Sennheiser ME66 microphone with a $\mathrm{K} 6$ powering module and a MZW66 foam windshield (Sennheiser Electronic GmbH, Germany) directing the microphone upwards. Recordings were made at a sampling rate of $44 \mathrm{kHz}$ and 16 bits resolution in uncompressed PCM format and saved as wav-files. Ten calls from the middle of a call-bout were analysed per individual. For each call we analysed call duration, call interval, calls per bout, and maximum, minimum and dominant frequencies. The spectral and temporal parameters were analysed, and the power spectra were calculated in Raven Pro 1.5 (Window: Blackman, DFT: 2048 samples, $3 \mathrm{~dB}$ filter bandwidth: $158 \mathrm{~Hz}$; Grid spacing $21.5 \mathrm{~Hz}$; overlap $70.1 \%$; Charif et al., 2004).
Lowest and highest frequencies were measured $10 \mathrm{~dB}$ below peak frequency, avoiding overlap with background noise (Simões \& Lima, 2011). Terminology used in the advertisement call description follows Zimmermann (1990) and Erdtmann \& Amézquita (2009). The call repetition rate was calculated as number of calls per call-bout duration. In case of heavy rainfall and/or wind, no recordings were made. Data from only the individual male at Loma Grande was used here to describe the entire calling behaviour of the species during the day.

\section{Diet}

The stomach content of captured adult males was extracted using the flushing method which has been previously employed in amphibians with no evidence of harm to the animals (Born et al., 2010). A small-modified pipette tip was gently introduced inside the mouth to reach the pharyngeal area. To induce regurgitation an influx of tap water was introduced using a syringe. The content was emptied on a Petri dish, then collected using a plastic pipette, and deposited in $2 \mathrm{ml}$ Eppendorf tubes with $10 \%$ formalin.

Insects were identified under a stereomicroscope (NIKON, model SMZ445: Nikon Instruments Inc.) to order and when possible to genus using the keys of Palacio \& Fernández (2003) and Krantz \& Walter (2009). The vast majority of samples were heavily digested, making a precise identification difficult.

To determine the niche breadth we calculated the Levins index (Levins, 1968) which accounts for the uniformity in resources consumed (in our case, insect orders) for each individual in each population. We also followed the calculation of the standardised Levins index as indicated in Krebs (1999).

\section{Data analysis}

Data were transformed in order to meet parametric assumptions; otherwise non-parametric tests were used. The main effects of independent variables on calling activity was assessed using ANOVA and their interaction assessed using ANCOVA. Post-hoc testing was used to evaluate differences in air temperature among sites (Benjamini-Hochberg tests) and differences in call properties between populations of O. vicentei (Bonferroni tests). The relationships between climatic variables and the call properties were evaluated by linear regression analyses. A value of $\mathrm{P}<0.05$ was considered significant. All values reported are mean $( \pm S E M)$ unless otherwise indicated. The analyses were undertaken in $\mathrm{R}$ v.3.4.3 (R Development Core Team, 2017).

\section{RESULTS}

\section{Biometric differences}

For biometric measurements, 21 adult males were captured at Loma Grande $(\mathrm{SVL}=17.33 \pm 0.01 \mathrm{~mm}$, mass $=0.35 \pm 0.01$ g), 11 at Isleta (SVL $=18.23 \pm 0.28 \mathrm{~mm}$, mass $=0.43 \pm 0.02$ g) and 9 at Alto Ortiga (SVL $=17.82 \pm 0.24 \mathrm{~mm}$, mass $=0.48$ $\pm 0.02 \mathrm{~g})$. There were no differences in body size among the three frog populations controlling for body mass (ANOVA; Site: $F_{2,36}=2.04, P=0.14$, Mass: $F_{1,35}=5.37, P=0.03$, Site 
$x$ Mass: $\left.F_{2,33}=1.20, P=0.31\right)$. However, body mass was different among sites (ANOVA; Mass: $F_{2,36}=16.84, P<0.001$ ) the values of Loma Grande being smaller than those of Isleta (post-hoc Bonferroni test, $\mathrm{P}=0.004$ ) and Alto Ortiga (posthoc Bonferroni test, $\mathrm{P}<0.001$ ) with no difference between Isleta and Alto Ortiga (post-hoc Bonferroni test, $\mathrm{P}=0.13$ ).

\section{Calling activity}

From all study sites combined we registered a total of 3042 callbouts, averaging $31.09 \pm 0.70$ call-bouts per hour from 07:00 $h$ to $10: 00 h$ and $10.86 \pm 0.30$ call-bouts per hour from 14:00 $\mathrm{h}$ to $17: 00 \mathrm{~h}$. Overall the number of call-bouts was affected by time of the day, with more call-bouts in the morning than the afternoon (ANOVA, Time: $F_{5,93}=3.92, P=0.003$, Fig. 2). There was a calling peak between 08:00 $\mathrm{h}$ and 10:00 $\mathrm{h}$, after which calling decreased with time across the day. In Isleta and Alto Ortiga in particular, peak calling activity occurred between 08:00 $\mathrm{h}$ and 09:00 h, while in Loma Grande peak was between 09:00 $\mathrm{h}$ and 10:00 h; in all three populations calling decreased in the afternoon (Supplementary material, Fig. 2). A single focal male from Loma Grande called 248 times from 06:17 $\mathrm{h}$ to $18: 05 \mathrm{~h}$, averaging 22.55 call-bouts per hour, with peaks in the morning between 07:00 $\mathrm{h}$ and 08:00 $h(n=22)$, around noon 12:00 $h(n=30)$ and around 17:00 h $(n=38)$. No calls for this focal male were recorded at 14:00 $h$ (Supplementary materials, Fig. 3).

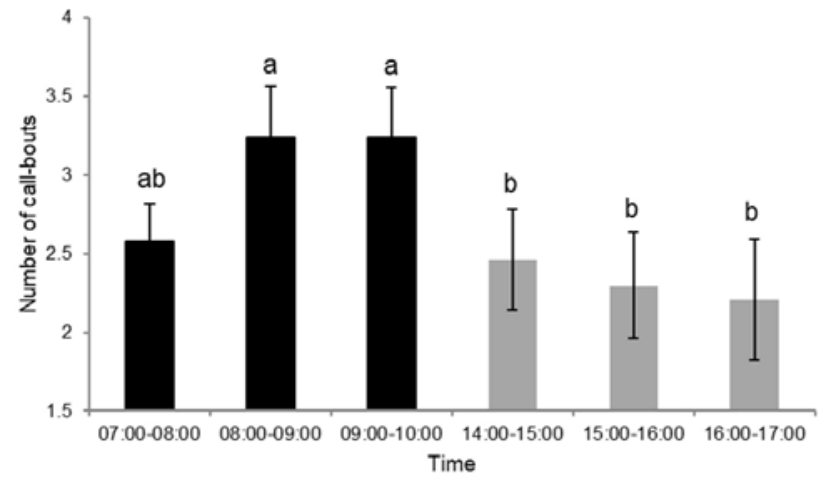

Figure 2. Calling activity differences between morning (black) and afternoon (grey) periods. To meet parametric assumptions number of call-bouts was transformed as $\log _{10}\left(\right.$ Calls $\left.h^{-1}+4\right)$. Values are means \pm SEM. Means without a letter in common are significantly different $(P \leq 0.05)$

Calling activity was affected also by season (ANOVA, Season: $F_{1,97}=4.75, P=0.032$ ), with higher calling activity during the dry season compared to the rainy season. However, there was no interaction between time of the day and season (ANCOVA, Time $x$ Season: $F_{5,87}=0.38, P=0.86$ ).

In our dataset, air temperature and air relative humidity were inversely correlated (Spearman, $S=272520$, rho $=$ $-0.73, P<0.01)$. Hence, to avoid autocorrelation, we chose one variable for inclusion in subsequent analyses. Air temperature differed among the three study sites (ANOVA, Site: $F_{2,95}=19.63, P<0.001$, Supplementary materials, Table 1). Air temperature was significantly higher in Alto Ortiga than at Isleta (post-hoc Benjamini-Hochberg test, $\mathrm{P}<0.001$ ) and was significantly higher in Alto Ortiga than at Loma Grande (post-hoc Benjamini-Hochberg test, $\mathrm{P}<0.001$ ). Air temperature was not different between Isleta and Loma Grande (post-hoc Benjamini-Hochberg test, $P=0.11$ ). The interaction between air temperature and site affected calling activity (ANCOVA, Temp x Site: $F_{2,92}=5.41, P<0.01$, Fig. 3 ).

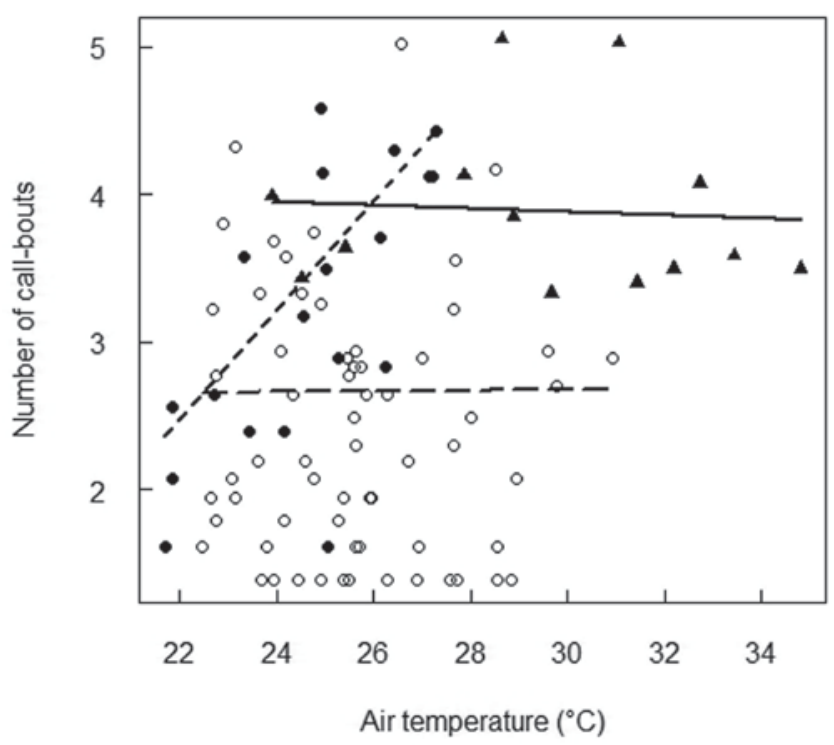

Figure 3. Interaction plot between site and air temperature on the number of call-bouts of $O$. vicentei. Filled circles and dash line represent Loma Grande; open circles and long dash line represent Isleta; the black triangles and solid line represent Alto Ortiga. To meet parametric assumptions number of call-bouts was transformed to $\log _{10}$ (Calls h-1+4)

\section{Bioacoustics}

A total of 7,322 calls from 41 male 0 . vicentei were analysed with a series of 29 to 290 pulsed calls in each call-bout (75.60 \pm 51.31 pulsed calls; Supplementary materials, Table 2).

Bouts had a duration of $24.25 \mathrm{~s}$ (range $4.57-51.61 \mathrm{~s}$, SEM $7.92, \mathrm{n}=230$ ) with intervals between bouts averaging $108 \mathrm{~s}$ (range 5.04-717.34 s, SD 128.41; $n=219$ ). The calls within a bout were repeated at a rate of 1.03 to 3.40 calls/second ( $2.35 \pm 0.48$ calls/second; Supplementary materials, Table 2 ). Call duration is variable (Coefficient of variation (CV): 28.52 ), ranging from $0.089-0.31 \mathrm{~s}$. The dominant frequency is less variable (CV: 4.65), at $5736.9 \mathrm{~Hz} \pm 266.76$ (Supplementary materials, Table 2). From the recorded calls of the single male at Loma Grande, we found that call-bouts are characterised by a large initial interval between individual calls; these intercall intervals become progressively shorter across the first approximately 10 calls (Supplementary materials, Fig. 4). After this the intercall interval becomes more homogenous, with the intercall intervals becoming roughly constant. There is also a progressive increase in call frequency, with the three first calls at lower frequency than the rest (pairwise $\mathrm{KW}, \mathrm{P}<0.05, \mathrm{n}=6329$, Supplementary materials, Fig. $5)$. It was not possible to measure the number of pulses per call, as we recorded in natural field conditions with 
most recordings overlapped with background noise. Most recorded frogs called from high in the canopy (from $5 \mathrm{~m}$ to $15 \mathrm{~m}$ approximately); the distance between the microphone and the focal frog was too great to obtain a better signal to noise ratio.

Air temperature was positively correlated with call-bout repetition rates $\left(R^{2}=17.5, P<0.05\right)$, and negatively correlated with call duration, but only for the Loma Grande population $\left(R^{2}=0.59, P<0.05, n=6\right.$; Supplementary materials, Fig. 6).

No correlation was found between these variables for Alto Ortiga ( $R^{2}=0.16, P>0.05, n=9$; Supplementary materials, Fig. 6) and Isleta $\left(R^{2}=7.13 e-4, P>0.05, n=21\right.$; Supplementary materials, Fig. 6). The dominant frequency was different between the populations of Alto Ortiga and Isleta (post-hoc Bonferroni test, P < 0.05; Fig. 4 \& Fig. 5). Data from Cerro Narices and Donoso populations were not included in this analysis due to small sample size.

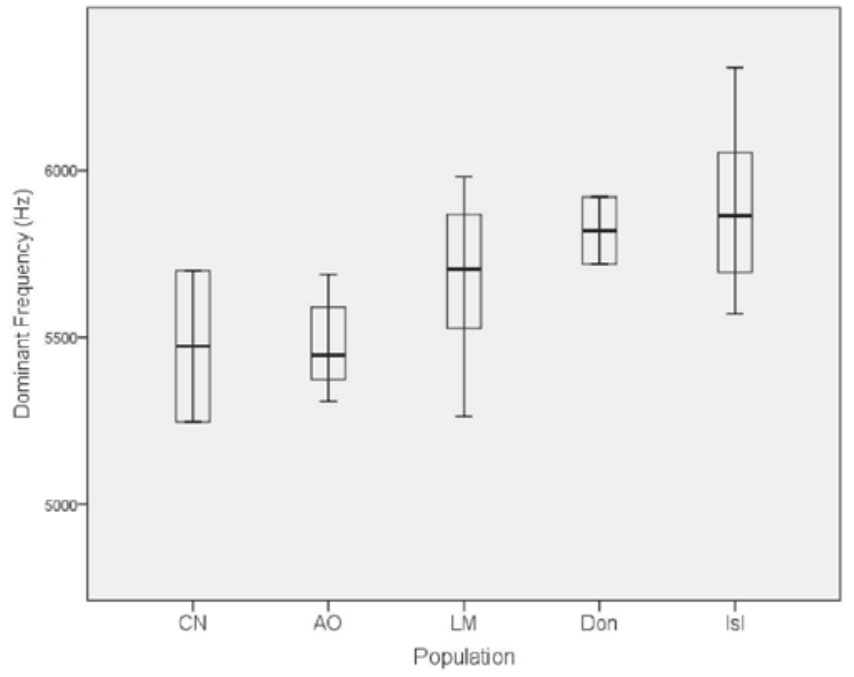

Figure 4. The dominant frequencies of the advertisement call of $O$. vicentei in our five study populations. We only found significant differences in dominant frequency between the Alto Ortiga and Isleta populations (post-hoc Bonferroni test, $p<0.05$ ). CN: Cerro Negro, AO: Alto Ortiga, LM: Loma Grande, Don: Donoso, Isl: Isleta

\section{Diet}

A total of 27 males were sampled for their stomach content, of which 10 were from Loma Grande (dry season), 8 from Isleta (dry and rainy season) and 9 from Alto Ortiga (rainy season). Although it was difficult to identify the items in the samples due to their advanced digested state, we found the arthropod orders Hymenoptera (ants), Diptera (flies) and Sarcoptiformes (oribatid mites) were common in all three populations, with Araneae (spiders) and Isopoda (isopods) present in smaller numbers (Fig. 6). In all three populations the ant genera identified were Solenopsis, Crematogaster and Tapinoma sp. near ramulorum, the last one a new inclusion in the diet of species of the genus Oophaga (Supplementary materials, Table 3).

There was no significant difference in niche breadth among the three populations according to the normal Levins index (ANOVA, Site: $F_{2,24}=0.057, P=0.94$, Supplementary materials, Table 4), nor the standardized Levins index (ANOVA, Site: $F_{2,24}$ $=1.58, P=0.22$, Supplementary materials, Table 4).

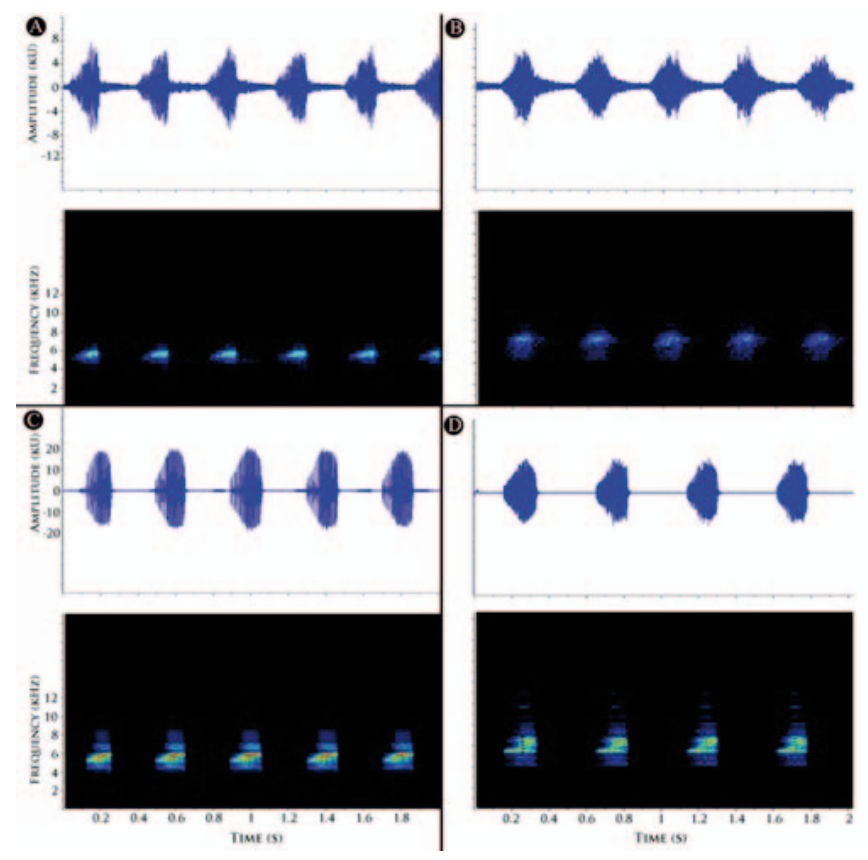

Figure 5. Oscillograms (above) and spectrograms (below, only dominant frequency is shown) of the advertisement calls for the populations of $O$. vicentei in this study; A) Isleta; B) Alto Ortiga; C) Cerro Narices; D) Donoso, Colón

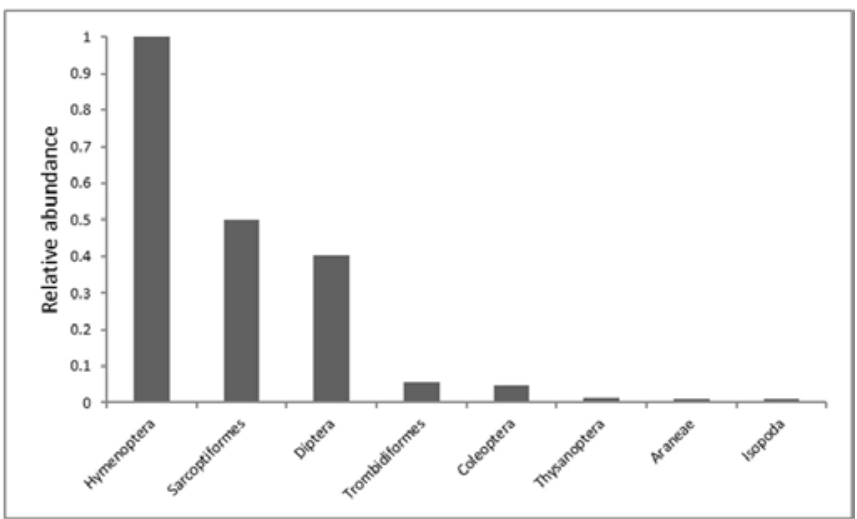

Figure 6. Relative abundance (proportion of frog stomach content) of arthropod orders found

\section{DISCUSSION}

Due to the logistical difficulties of studying this small, cryptic and arboreal species, we were unable to estimate with confidence the number of frogs calling at each site. With the obvious limitations we used number of call-bouts heard as an indicator of calling activity. To our knowledge this is the first time activity patterns have been described for an arboreal dendrobatid species. Overall our results indicate that 0 . vicentei males show peak calling activity between 08:00 $\mathrm{h}$ and 10:00 $\mathrm{h}$, with decreased calling across the afternoon (Fig. 2). Our results are similar to findings for Oophaga pumilio, closely related to $O$. vicentei, which shows peak calling activity between 08:00 $\mathrm{h}$ and 10:00 h. In that species males call from spots on the ground or just above ground in the understorey vegetation (Bunnell, 1973) and this activity peaks in the morning between 07:45 $\mathrm{h}$ and 09:15 $\mathrm{h}$ (Graves, 
1999). Oophaga vicentei spends most of its time high in trees (but see Peña et al., 2016), and as such may receive increased levels of early morning light triggering calling behaviour earlier than in ground dwelling frogs.

Overall calling activity during the dry season was higher than during the rainy season. Anuran calling activity is known to fluctuate with the onset of seasons especially in temperate environments (Saenz et al., 2006). The mountainous conditions in Santa Fe result in a dry season (December to April) marked by trade winds with increased hours of sunlight, and sporadic showers and fog during early morning at elevated sites (Macinnis-Ng et al., 2014). Although we did not measure rainfall during our study, mean values of relative humidity were above $80 \%$ during dry season months, allowing dew formation to fill bromeliad axils with water, a suitable location for $O$. vicentei reproduction (Lötters et al., 2007).

In Loma Grande, air temperature was positively correlated with calling activity, unlike the other two sites (Fig. 3). Loma Grande was at the highest elevation (750 $\mathrm{m}$ a.s.l.), situated on the continental divide that separates the Pacific from the Caribbean slopes of Panama, and was subject to cooler air than the sites at lower elevations (Supplementary materials, Table 1). However, we cannot conclude that these results are due to population differences alone since, we have not estimated the number of calling frogs from each population. In amphibians, an increase in ambient temperature may elicit higher metabolism (Rome et al., 1992), hence for the frogs at Loma Grande a slight increase in air temperature could have boosted calling activity.

The calls of $O$. vicentei were similar among the populations, with differences primarily in dominant frequency. However, the calls of $O$. vicentei can be distinguished from the calls of other Oophaga spp. from western Panamá, by multiple acoustic parameters, including dominant frequency (DF), call duration $(\mathrm{CD})$ and call rate $(\mathrm{CR})$, as follows: O. vicentei (DF $=5736.9 \mathrm{~Hz}, \mathrm{CD}=0.17 \mathrm{~s}, \mathrm{CR}=5.32 \mathrm{Calls} / 2 \mathrm{~s}$; this study); $O$. granulifera $(\mathrm{DF}=4010, \mathrm{CD}=0.38, \mathrm{CR}=4$ calls $/ 2 \mathrm{~s}$, in: Erdtmann \& Amézquita, 2009; Myers \& Daly, 1976), O. pumilio (DF $=4856, \mathrm{CD}=0.043 \mathrm{~s}, \mathrm{CR}=7.8$ Calls $/ 2 \mathrm{~s}$; in: Erdtmann \& Amézquita, 2009; Myers \& Daly, 1976) and O. arborea (DF $=4364, C D=0.107, C R=6.25$ Calls $/ 2 \mathrm{~s}, \mathrm{n}=10$, this study, see Supplementary materials, Figure 1).

Most published analyses of frog vocalisations usually include only single calls. Oophaga spp. from western Panama, however, calls in bouts. To our knowledge, ours is the first description of the entire series of call-bouts of an Oophaga spp. We found cline variation within the ten first calls within a call-bout in $O$. vicentei in dominant frequency, call duration and silent intervals. Particularly, the first call is spaced from the second call by almost double the silent interval between two calls in the middle of the call-bout. While the significance of this call structure is unknown, it is possible that the presence of this isolated call within a call-bout could convey information to receivers, but the importance of this in $O$. vicentei acoustic communication has yet to be determined.

We found differences in dominant frequency among the populations from Santa Fe National Park. Although we did not measure the body size of specific calling males, there were no significant differences between the body sizes among specimens collected from different sites, only in terms of body mass. Body size can be negatively correlated with dominant frequency, with larger frogs calling at lower frequencies and vice versa (Gerhardt \& Huber, 2002; Erdtmann \& Amézquita, 2009). However, for at least some Oophaga spp., this is not the case as no correlation has been found between body size and dominant frequency (Prohl, 2003; Vargas-Salinas \& Amézquita, 2013), even though other species can vary their dominant frequency by increasing their vocal cord mass or adjusting its tension (Ryan \& Drewes, 1990; Vargas-Salinas \& Amézquita, 2013). With the data we have, we could not determine whether the differences found in dominant frequency are an artefact of body size or mass alone, as we were unable to measure calling males. Differences in frequency could also be due to geographic distances. We found no frequency differences between the Loma Grande and Isleta populations, on the Continental Divide and the Pacific slope, respectively, but did find differences between these and the Alto Ortiga population, on the Caribbean slope. Average dominant frequency values for the Cerro Narices population, which is on the Pacific slope, were however similar to those from Alto Ortiga. Nevertheless, variation in dominant frequency has been found among other Oophaga spp., and could be explained by geographical distances, isolation or the selective pressure of habitat (Myers \& Daly, 1976; Prohl, 2003; Vargas-Salinas \& Amézquita, 2013). Despite this difference in dominant frequency we did not find differences in the coefficient of variation (CV), which was similar among all populations. Since the CV is a less variable trait (than dominant frequency itself), evaluating differences between individuals or populations could be important in taxonomic differentiation. We would argue that the differences we found in the raw values of dominant frequency among populations are not enough to differentiate these populations as distinct taxonomic units using this trait alone.

Temperature can affect temporal properties in ectotherms (Gerhardt \& Huber, 2002). As in its congener, O. pumilio, temperature influenced the temporal call properties in $O$. vicentei: in both species, temperature was positively correlated to call repetition rates and negatively correlated to call duration (Myers \& Daly, 1976; Prohl, 2003). Although call duration was significantly negatively correlated to temperature for the population at Loma Grande, only a slightly negative relationship was found for the other two populations. After removing the effect of temperature, we did not detect significant differences among populations in either call repetition rates or call duration.

The diet of our sampled males was dominated by arthropods, mainly ants and oribatid mites, which have been described in the diet of other species of dendrobatids linked to a bioaccumulation of defensive alkaloids (Saporito et al., $2009 \& 2012$ ). Ants were common in the diet of the three study populations (Supplementary materials, Table 3) including the genus Solenopsis which is known as a source of pumiliotoxin alkaloids for defensive purposes in poison frogs (Saporito et al., 2004). It was interesting to also discover ants 
of the genus Tapinoma as part of the diet of $O$. vicentei as they are known to contain the repellent alkaloid actinidine (Tomalski et al., 1987) although this has not been identified as a defensive alkaloid in 0 . vicentei. Oribatid mites also represent an important part of the alkaloid provision in poison frogs (Saporito et al., 2007). There is evidence of a diverse array of alkaloids shared between mites and $O$. pumilio poison frogs, some of them also found in O. vicentei, e.g. indolizidines and pumiliotoxins (Saporito et al., 2004). Our samples represent just a snapshot of the potential variation in the diet in wet and dry seasons in each population.

The observation we have described on the ecology and behaviour of $O$. vicentei in the wild are an essential contribution to a better understanding of the conservation status of this species. This study has opened the door to future studies on this endemic, data deficient species.

\section{ACKNOWLEDGEMENTS}

Dineylis Aparicio, Iliana Cisneros, Katherine Rodríguez, Reyna Tuñón, Joelbin De la Cruz, Amarilis Ramos, Seferino Rodríguez, Enoc Bordones, Celestino Flores and Carlos Abrego helped with field data collection. Special thanks to Damond Kyllo for help with the map design and Beulah Garner and Philip Ward for their help with ant identification. Thanks to Prof. Roger Downie for useful comments to the draft version of the manuscript. This work was conducted under the Scientific permit SE/A-115-15 issued by The Ministry of Environment of Panama, the IACUC protocol number 2016-0101-2019-4 from the Smithsonian Tropical Research Institute and with special thanks to a grant from Sistema Nacional de Investigación (SNI) contract 47-2015 in Panama.

\section{REFERENCES}

Born, M., Bongers, F., Poelman, E.H. \& Sterck, F.J. (2010). Dry-season retreat and dietary shift of the dart-poison frog Dendrobates tinctorius (Anura: Dendrobatidae). Phyllomedusa 9: 37-52.

Bunnell, P. (1973). Vocalizations in the territorial behavior of the frog Dendrobates pumilio. Copeia 1973: 277-284.

Charif, R.A., Clark, C.W. \& Fristrup, K.. (2004). Raven 1.3 User's Manual. Cornell Laboratory of Ornithology. 191 pp.

Daly, J.W., Secunda, S.I., Garrafo, H.M., Spande, T.F., Wisnieski, A. \& Cover, J.F.J. (1994). An uptake system for dietary alkaloids in poison frogs (Dendrobatidae). Toxicon 32: 657-663.

Dorcas, M.E., Price, S.J., Walls, S.C. \& Barichivich, W.J. (2010). Auditory monitoring of anuran populations. In Amphibian Ecology and Conservation: A Handbook of Techniques, 281298 pp. Dodd, C.K.(Ed). Oxford University Press, Oxford, UK.

Erdtmann, L. \& Amézquita, A. (2009). Differential evolution of advertisement call traits in dart-poison frogs (Anura: Dendrobatidae). Ethology 115: 801-811.

Gerhardt, H.C. \& Huber, F. (2002). Acoustic Communication in Insects and Anurans: Common Problems and Diverse Solutions. University of Chicago Press. 531 pp.

Graves, B.M. (1999). Diel activity patterns of the sympatric poison dart frogs, Dendrobates auratus and D. pumilio, in
Costa Rica. Journal of Herpetology 33: 375-381.

IUCN SSC Amphibian Specialist Group (2019). Oophaga vicentei. The IUCN Red List of Threatened Species 2019: e.T55209A54344862. http://dx.doi.org/10.2305/IUCN. UK.2019-1.RLTS.T55209A54344862.en. Downloaded on 25 April 2019.

Jungfer, K.-H., Weygoldt, P. \& Juraske, N. (1996). Dendrobates vicentei, eun neuer Pfeilgiftrosch aus Zentral-Panama. Herpetofauna 18: 17-26.

Krantz, C.W. \& Walter, D.E. (2009). A Manual of Acarology. 3d edn. Texas Tech University Press, Lubbock, Texas, USA. $816 \mathrm{pp}$.

Krebs, C.J. (1999). Ecological Methodology. 2nd edn. AddisonWesley Educational Publishers Inc, New York, USA. 624 pp.

Levins, R. (1968). Evolution in changing environments: some theoretical explorations. Princeton University Press, Princeton, New Jersey. 132 pp.

Lötters, S., Jungfer, K.-H., Henkel, W. \& Schmidt, F.W. (2007). Poison frogs. Biology, species and captive husbandry. Chimaira Editions, Frankfurt am Main, Germany. 549 pp.

Macinnis-Ng, C., Flores, E.E., Müller, H. \& Schwendenmann, L. (2014). Throughfall and steamflow vary seasonally in different land-use types in a lower montane tropical region of Panama. Hydrological Processes 28: 2174-2184.

Myers, C.W. \& Daly, J.W. (1976). Preliminary evaluation of skin toxins and vocalizations in taxonomic and evolutionary studies of poison-dart frogs (Dendrobatidae). Bulletin of the American Museum of Natural History 157: 173-262.

Palacio, E. \& Fernández, F. (2003). Claves para las subfamilias y géneros. In Introducción a las hormigas de la región Neotropical, 233-260 pp. Humboldt, I. de I. de R.B.A. von (Eds). Bogotá, Colombia.

Peña, B., Gracia, V. De \& Flores, E.E. (2016). Habitat use: Oophaga vicentei (Vicente's poison frog). Herpetological Review 47: 114.

Prohl, H. (2003). Variation in male calling behaviour and relation to male mating success in the strawberry poison frog (Dendrobates pumilio). Ethology 109: 273-290.

R Development Core Team. (2017). R: a language and environment for statistical computing.

Rasband, W.S. (1997). ImageJ. U. S. National Institutes of Health, Bethesda, Maryland, USA.

Rodrigues, A.S.L., Pilgrim, J.D., Lamoreaux, J.F., Hoffmann, M. \& Brooks, T.M. (2006). The value of the IUCN Red List for conservation. Trends in Ecology and Evolution 21: 71-76.

Rome, L.C., Stevens, E.D. \& John-Alder, H.B. (1992). The influence of temperature and thermal acclimation on physiological function. In Environmental Physiology of the Amphibians, 183-205 pp. Feder, M.E. \& Burggren, W.W. (Eds). University of Chicago Press, Chicago. IL.

Ryan, M.J. \& Drewes, R.C. (1990). Vocal morphology of the Physalaemus pustulosus species group (Leptodactylidae): morphological response to sexual selection for complex calls. Biological Journal of the Linnean Society 40: 37-52.

Saenz, D., Fitzgerald, L.A., Baum, K.A. \& Richard, N. (2006). Abiotic correlates of anuran calling phenology: the importance of rain, temperature, and season. Herpetological Monographs 20: 64-82.

Saporito, R.A., Donnelly, M.A., Norton, R.A., Garraffo, M., 
Spande, T.F. \& Daly, J.W. (2007). Oribatid mites as a major dietary source for alkaloids in poison frogs. Proceeding of the National Academy of Science of the USA 104: 8885-8890.

Saporito, R.A., Donnelly, M.A., Spande, T.F. \& Garraffo, H. M. (2012). A review of chemical ecology in poison frogs. Chemoecology 22: 159-168.

Saporito, R.A., Garrafo, H.M., Donnelly, M.A., Edwards, A.L., Longino, J.T. \& Daly, J.W. (2004). Formicine ants: an arthropod source for the pumiliotoxin alkaloids of dendrobatid poison frogs. Proceedings of the National Academy of Sciences of the USA 101: 8045-8050.

Saporito, R.A., Spande, T.F., Garraffo, H.M. \& Donnelly, M.A. (2009). Arthropod alkaloids in poison frogs: a review of the "dietary hypothesis." Heterocycles 79: 277-297.

Simões, P.I. \& Lima, A.P. (2011). The complex advertisement calls of Allobates myersi (Pyburn, 1981) (Anura: Aromobatidae) from São Gabriel da Cachoeira, Brazil. Zootaxa 2988: 66-68.
Tomalski, M.D., Blum, M.S., Jones, T.H., Fales, H.M., Howard, D.F. \& Passera, L. (1987). Chemistry and functions of exocrine secretions of the ants Tapinoma melanocephalum and T. erraticum. Journal of Chemical Ecology 13: 253-263.

Vargas-Salinas, F. \& Amézquita, A. (2013). Stream noise, hybridization, and uncoupled evolution of call traits in two lineages of poison frogs: Oophaga histrionica and Oophaga lehmanni. PLOS ONE 8: e77545.

Zimmermann, E. (1990). Behavioral signals and reproduction modes in the neotropical frog family Dendrobatidae: Proceedings of the First international symposium on biology and physiology of amphibians held at Karlsruhe. In Biology and Physiology of Amphibians, 61-73 pp. Hanke, W. (Ed). Gustav Fischer Verlag, Stuttgart.

Accepted: 27 July 2019

Please note that the Supplementary Material for this article is available online via the Herpetological Bulletin website: https://thebhs.org/publications/the-herpetological-bulletin/issue-number-149-autumn-2019 